\title{
A ESTATÍSTICA DO CRIME NO OITOCENTOS POR FRANCISCO JOSÉ VIVEIROS DE CASTRO: DADOS DO BRASIL E DO RIO DE JANEIRO
}

\author{
Adriana Gomes \\ Secretaria Estadual de Educação Rio de Janeiro (SEEDUC/RJ), Brasil \\ E-mail: adrigomes.rj@outlook.com \\ ORCID: https://orcid.org/0000-0002-2220-4456
}

Data de recebimento: $12 / 02 / 2020$

Data de aprovação: 25/03/2020

DOI: $\underline{\text { https://doi.org/10.30612/frh.v22i39.12575 }}$

Resumo: A partir da análise da fonte histórica Ensaio sobre a estatística criminal da República, escrito pelo magistrado Francisco José Viveiros de Castro sob a solicitação do Chefe da Polícia do Distrito Federal Manuel Prisciliano de Oliveira Valladão, traçamos a trajetória da estatística criminal do Brasil de 1865 a 1872 e do Rio de Janeiro de 1870 a 1888. A proposta de Viveiros de Castro foi organizar os dados dos crimes e dos criminosos para que intervenções pudessem ocorrer para a reversão do quadro. O juiz ao apresentar o seu trabalho nos evidenciou sua interpretação dos números sob a perspectiva da Nova Escola Penal.

Palavras-Chave: História do Direito. Francisco José Viveiros de Castro. História do Crime. Estatística Criminal do século XIX. Nova Escola Penal.

\section{THE STATISTICS OF CRIME IN THE EIGHT HUNDRED BY FRANCISCO JOSÉ VIVEIROS DE CASTRO: DATA FROM BRAZIL AND RIO DE JANEIRO}

\begin{abstract}
From the analysis of the historical source Essay on criminal statistics of the Republic written by magistrate Francisco José Viveiros de Castro at the request of the Chief of Police of the Federal District Manuel Prisciliano de Oliveira Valladão we trace the trajectory of criminal statistics in Brazil from 1865 to 1872 and Rio de Janeiro from 1870 to 1888. Viveiros de Castro's proposal was to organize data on crimes and criminals so that interventions could occur to reverse the situation. The judge, when presenting his work, showed us his interpretation of the numbers from the perspective of the New Penal School.
\end{abstract}

Keywords: History of Law. Francisco José Viveiros de Castro. History of Crime. Criminal Statistics of the 19th century. New Penal School.

\section{LAS ESTADÍSTICAS DEL CRIMEN EN LOS OCHOCIENTOS POR FRANCISCO JOSÉ VIVEIROS DE CASTRO: DATOS DE BRASIL Y RÍO DE JANEIRO}

Resumen: Del análisis de la fuente histórica Ensayo sobre estadísticas penales de la República escrito por el magistrado Francisco José Viveiros de Castro a solicitud del jefe de 
policía del Distrito Federal Manuel Prisciliano de Oliveira Valladão, trazamos la trayectoria de las estadísticas penales en Brasil de 1865 a 1872 y Río de Janeiro de 1870 a 1888 . La propuesta de Viveiros de Castro fue organizar datos sobre crímenes y delincuentes para que pudieran ocurrir intervenciones para revertir la situación. El juez, al presentar su trabajo, nos mostró su interpretación de los números desde la perspectiva de la Nueva Escuela Penal.

Palabras Clave: Historia del Derecho. Francisco José Viveiros de Castro. Historia del Crimen. Estadísticas Penales del siglo XIX. Nueva Escuela Penal.

\section{Introdução}

Em seus estudos para compreender os rumos da criminalidade, o juiz Francisco José Viveiros de Castro ${ }^{1}$ (1862-1906) se debruçou em escrever o Ensaio sobre a estatística criminal da República após a solicitação da organização pelo Chefe da Polícia do Distrito Federal Manuel Prisciliano de Oliveira Valladão² (1849-1921).

O juiz criminal, em suas considerações acerca da organização dos crimes, ressaltou que o "homem do século XIX só acreditava nos fatos verificados, traduzidos em algarismos" e as estatísticas seriam o espelho da sociedade por promoverem a sua avaliação nos casos criminalistas (CASTRO, 1894, p. 3).

O nosso propósito é analisar as considerações de Viveiros de Castro sobre o levantamento estatístico realizado por ele, por isso destacaremos as suas discussões acerca dos números na dinâmica do crime. Entretanto, antes de nos debruçarmos nessas interpelações traçaremos, inicialmente, uma breve trajetória das estatísticas criminais no Brasil e como se coordenou a organização dos dados discutidos ao longo do trabalho. No segundo e terceiro momento evidenciaremos os dados do crime revelados em números tanto no Brasil (de 1865 a 1872) quanto no Rio de Janeiro (de 1870-1888).

\footnotetext{
1 O maranhense Francisco José Viveiros de Castro foi um jurista criminal de importância ímpar para a jurisprudência brasileira que atuou com destaque no Rio de Janeiro nos anos finais do oitocentos. Por se assenhorear de relevante engajamento às causas emergenciais da sociedade, ele se posicionava à frente de muitos de seus contemporâneos. Por inúmeras vezes, não se furtou de emitir aos seus pares os seus pareceres sobre casos polêmicos e controversos na esfera criminal da sociedade de sua época, por meio de diversos livros publicados. Sua maior preocupação era disponibilizar aos jovens a oportunidade de instigar o conhecimento jurídico atendendo a métodos de observação e a possibilidade de apreensões mediante as investigações cuidadosas dos fatos a partir de suas percepções jurídicas da Nova Escola Penal, sobretudo da Escola Positiva do Direito (GOMES, 2017, p. 22; 88).

O sergipano Manuel Prisciliano de Oliveira Valadão foi nomeado Chefe de Polícia do Distrito Federal em 1893 e no exercício do cargo atuou no combate da Revolta da Armada (1893-1894), dirigida pelo Almirante Custódio de Melo (1840-1902), cabendo-lhe a tarefa de sufocar o movimento de rebelião da Marinha. O Chefe de Polícia, que antes de assumir a função havia sido secretário particular do Presidente Marechal Floriano Peixoto (1839-1895), manteve-se no cargo até 1894, quando se responsabilizou pelo governo do estado de Sergipe no biênio (1894-1896) (DORIA, 1949, p. 2-3).
} 
E a partir da apropriação dessas informações, finalmente analisaremos as percepções de Viveiros de Castro imbuídas de pressupostos da Nova Escola Penal ${ }^{3}$ com discussões historiográficas a respeito do crime na Capital Federal.

\section{Trajetória das Estatísticas Criminais no Brasil}

A proposta de se utilizar dados estatísticos para se compreender e atuar contra a criminalidade iniciou no Brasil na ocasião do Decreto 3572 de 30 de dezembro de 1865 expedido pelo Ministro e Secretário de Estado dos Negócios da Justiça José Thomaz Nabuco de Araújo $^{4}$ (1813-1878). Havia se verificado a necessidade de se quantificar e qualificar as transgressões penais para tentar combatê-las mediante o entendimento da dinâmica da criminalidade regulamentada na estatística policial e judiciária (BRASIL, 1865).

A proposta organizada por Nabuco de Araújo era que ao final de cada ano se coletassem os dados para o ano seguinte serem estruturados e no ano subsequente disponibilizados. Dessa maneira, os dados de 1865 seriam organizados em 1866 e apresentados ao poder legislativo em 1867 no final do ano. Seguindo essa ordenação, no final de dez anos todas as estatísticas seriam reduzidas em uma só "estatística relativa ao decênio", que se sistematizariam em um grande mapa anual e por toda a década (BRASIL, 1865).

A estatística policial consistiria em evidenciar as detenções e prisões preventivas, os habeas corpus, a movimentação de imigrantes, os suicídios, os acidentes nas estradas (ferro, minas e oficinas), entre outras (BRASIL, 1865).

Já a estatística judiciária seria dividida em criminal, civil, comercial e penitenciária. A premissa básica seria possibilitar acessibilidade aos crimes ocorridos e enquadrá-los em diferentes aspectos, tais como: a periculosidade, a responsabilidade, as características dos criminosos etc. Além disso, mapear as motivações para o crime, as quais as principais consideradas seriam o ódio ou a vingança, a miséria ou a cobiça, a rixa ou as altercações, a dissensão de família, a devassidão, entre outros motivos diversos (BRASIL, 1865).

A estatística civil se debruçaria em analisar as conciliações, as apelações, as execuções cíveis, os inventários, os testamentos, as hipotecas, os divórcios, as curatelas, as

\footnotetext{
3 Nova Escola Penal foram ideias desenvolvidas na Europa a partir dos trabalhos de Lombroso (1835-1909) e de seus seguidores. Essas ideias foram assimiladas por intelectuais brasileiros, especialmente pelos juristas da virada do século XIX para o XX.

$4 \quad$ Nabuco de Araújo foi jurista, ministro da justiça e membro do II Conselho de Estado que tinha grande apreço pelos utilitaristas e, sobretudo, pelos escritores liberais que atuavam como historiadores a serviço de seus Estados Nacionais no oitocentos (MOMESSO, 2001, p. 2-3).
} 
alienações de imóveis, entre outras situações de ordem cível. Já a estatística penitenciária teria a finalidade de revelar o movimento da punição das galés, dos condenados a prisão com trabalho, os condenados à prisão, a capacidade e o estado das prisões, entre outras especificações (BRASIL, 1865).

Entretanto, apesar da proposta ter a intenção bastante clara e com plena condição de execução, os dados coletados na estatística definida em 1865 ficaram aquém do projeto. Pelo menos o propósito inicial definido por Nabuco de Araújo não foi atingido, pois a coleta de dados foi insatisfatória. Por conta disso, em 17 de agosto de 1878 por meio do Decreto 7001 , o Ministro e Secretário de Estado dos Negócios da Justiça Lafayette Rodrigues Pereira ${ }^{5}$ (1834-1917) regulamentou outra Estatística Policial e Judiciária com o objetivo de também tentar realizar uma análise aprofundada da situação criminal (BRASIL, 1878).

O novo decreto regulamentou que as estatísticas definiriam os registros tanto de ordem policial e judicial. Eles teriam como referência o ano corrente de 1878, que seriam finalizadas em 1879 com apresentação ao Poder Legislativo em 1880. A dinâmica proposta seria constante nos anos subsequentes e no final do decênio as estatísticas se unificariam. A organização logística não seria tão diferente do decreto anterior (BRASIL, 1878).

As similaridades com o Decreto de 1865 foram tantas que, segundo Francisco José Viveiros de Castro (1894, p. 11) a deliberação também não foi executada com o êxito esperado. O jurista atribuiu o insucesso a "confusa" produção textual, que o fez aquém em comparação ao decreto anterior.

Ante a este malogro foi criada outra resolução, o Decreto de 8375 de 14 de dezembro de 1882, como mais uma tentativa de se organizar estatisticamente a ocorrência dos crimes com o propósito de simplificar os trâmites burocráticos dos decretos anteriores (BRASIL, 1882).

De acordo com o instituidor do novo decreto, o Conselheiro de Estado, Senador do Império, Ministro e Secretário de Estado dos Negócios da Justiça Manoel Pinto de Souza $\operatorname{Dantas}^{6}$ (1831-1894), o escopo da deliberação se manteria igual o anterior, só a logística que

\footnotetext{
$5 \quad$ O mineiro Lafayette Rodrigues Pereira formou-se em Direito e era um estudioso da Literatura e Filosofia. Grande parte de sua vida dedicou-se ao jornalismo e a advocacia com a publicação de livros. No Rio de Janeiro ocupou a cadeira de Ministro da Justiça e, também, a função de senador representando a sua província natal. Em 1883, tornou-se Ministro da Fazenda e como era estudioso da área de Direito Internacional prestou serviços importantes no setor para a monarquia. Com a Proclamação da República, passou a se dedicar novamente à área do Direito (PEREIRA, 2004, p. 375).

Manoel Pinto de Sousa Dantas formou-se em Bacharel pela Faculdade de Direito do Recife. Foi deputado provincial, deputado geral pela Bahia em diversos mandatos, membro do Conselho de Estado e ocupou a vaga no Senado em 1878. Foi ministro da Justiça entre 1880 e 1882, e interinamente Ministro do Império, no $28^{\circ}$ Gabinete, presidido pelo Conselheiro José Antônio Saraiva. Senador Dantas organizou e
} 
seria diferente. Todos os documentos da organização da estatística policial, judiciária e penitenciária seriam enviados pela Secretaria de Estado dos Negócios da Justiça à $3^{\mathrm{a}}$ Diretoria dos Negócios do Império. Nesse órgão a Seção de Estatística realizaria os serviços regulamentados. A intenção era simplificar a burocracia, pois a remessa dos documentos necessários para a composição dos trabalhos passaria a ficar ao encargo da sobredita Diretoria sem a intermediação da Secretaria de Justiça. Mas o decreto não foi efetivamente implementado e, mais uma vez, as estatísticas não foram organizadas (BRASIL, 1882).

Nesse panorama de indefinições com decretos instituídos e não executados como planejados e com a intenção de sistematizá-los para entender a dinâmica dos crimes e dos criminosos para a possível elaboração de ações no combate à criminalidade, que Manuel Prisciliano de Oliveira Valladão solicitou a Viveiros de Castro a organização dos dados da Estatística Criminal da República em 1894 com o material que estava disponível, mas descomposto.

\section{A organização das estatísticas: os dados do crime no Brasil apresentados por Viveiros de Castro}

Antes de evidenciarmos os dados organizados por Francisco José Viveiros de Castro, para termos razoável compreensão dos números acreditamos que vale ressaltarmos os dados demográficos. Acreditamos que as interpretações das estatísticas criminais podem ficar mais inteligíveis ao confrontarmos esses números relacionados à população com o quantitativo de transgressores ao longo dos anos.

Em 1872, a população brasileira totalizava em 9.930.478 habitantes, sendo 5.123.869 homens e 4.806.609 mulheres. Já no recenseamento de 1890 a população brasileira já apresentava significativo crescimento, totalizando em 14.333.915 habitantes em que 7.237.932 seriam homens e 7.095.983 seriam mulheres (IBGE, 1996).

Viveiros de Castro realizou o levantamento do quantitativo de criminosos no Brasil de 1865 a 1872 com a evidenciação dos números dos crimes, dos processos abertos, da natureza dos crimes públicos, particulares e policiais, contra a propriedade e personalidade, entre outros. Ainda se ocupou em destacar o quantitativo de transgressores penais maiores e menores de idade, gênero, divisão entre brasileiros e estrangeiros. Além disso, nos mostrou a

presidiu o $32^{\circ}$ Gabinete, que governou o país de 1884 a 1885, quando também ocupou o Ministério da Fazenda e, interinamente, o dos Estrangeiros. O marco de seu governo foi o grande impulso que deu ao abolicionismo, que ultrapassou a premissa básica de libertação dos escravizados, tendo em vista que defendeu uma ampla reforma social que tivesse abrangência em outros assuntos, entre eles reforma agrária e democratização do ensino (MANUEL..., 2018). 
situação nas Casas de Detenção por meio dos dados relacionados as especificidades das pessoas detidas e as dinâmicas nas Casas (CASTRO, 1894, p. 11).

No acumulado dos crimes ocorridos e catalogados estatisticamente entre os anos de 1865 ao ano de 1872 , os dados sinalizaram que 27.130 crimes haviam sido cometidos no país. Porém, devemos destacar que os dados estatísticos obtidos em alguns anos tiveram critérios diferenciados de contabilização. Além disso, ressaltamos que em determinados anos províncias específicas não tiveram seus crimes somatizados na estatística geral do Brasil. Em 1865 não foram adicionados os crimes ocorridos no Piauí, Amazonas, Maranhão, Rio Grande do Norte, Pernambuco, Sergipe, São Paulo e Rio Grande do Sul e, em 1871, não foram registrados os dados de Amazonas, Piauí, Goiás e Mato Grosso (CASTRO, 1894, p. 18, 25).

A natureza dos crimes públicos foi registrada entre 1865 e 1872 em 1.577. Já os crimes particulares ficaram quantificados em 23.444 e nos crimes policiais em 2.137. Os delitos contra a personalidade tiveram o quantitativo de 3.194 homicídios, 1.245 tentativas de homicídios, 7.800 ofensas físicas, 1.087 calúnias e injúrias, 315 ameaças e 269 estupros (CASTRO, 1894, p. 25).

Nos crimes contra a propriedade totalizaram 2.145 furtos, 866 roubos, 522 estelionatos e 503 danos. E nos termos viver bem foram assinadas 843 ocorrências, sendo 657 promovidos por homens e 186 por mulheres (CASTRO, 1894, p. 25).

Assim posto, com a proposta de tornar mais esclarecida a estatística dos números das transgressões penais de 1865 até 1872 no Brasil, criamos um quadro com a sistematização e expedientes relacionados ao crime a partir dos dados organizados no trabalho de Viveiros de Castro para o chefe de polícia. A nossa ordenação segue abaixo:

\section{Quadro I}

\section{Dados da Estatística dos crimes e criminosos do Brasil de 1865 a 1872}

\begin{tabular}{|c|c|c|c|c|c|c|c|c|}
\hline Anos & 1865 & 1866 & 1867 & 1868 & 1869 & 1870 & 1871 & 1872 \\
\hline Número de crimes & 1.970 & 3.400 & 3.163 & 3.155 & 4.804 & 4.001 & 3.658 & 2.979 \\
\hline Número de Processos $^{7}$ & 1.926 & 2.528 & 2.454 & - & - & 2.958 & 2.653 & 2.194 \\
\hline Número de Delinquentes $^{7}$ & 2.332 & 3.906 & - & - & - & 4.657 & 4.106 & 8.468 \\
\hline Conhecidos $^{\text {Desconhecidos }}$ & 2.094 & 3.455 & - & - & - & 4.328 & 3.858 & 3.297 \\
\hline Natureza dos Crimes & 238 & 451 & - & - & - & 329 & 248 & 171 \\
\hline Públicos & 131 & 214 & 256 & 188 & 283 & 226 & 157 & 122 \\
\hline Particulares & 1.572 & 2.812 & 2.744 & 2.809 & 4.061 & 3.474 & 3.163 & 2.809 \\
\hline Policiais & 267 & 374 & 163 & 158 & 460 & 301 & 366 & 48 \\
\hline $\begin{array}{c}\text { Natureza dos crimes } \\
\text { públicos }\end{array}$ & & & & & & & \\
\hline
\end{tabular}

O termo "delinquente" era recorrentemente utilizado nos estudos do crime nos anos finais do oitocentos. Mantivemos a referência original ao nos referirmos aos infratores. 
Fronteiras: Revista de História

A estatística do crime no oitocentos por Francisco José Viveiros de Castro: dados do Brasil e do Rio de Janeiro Adriana Gomes

\begin{tabular}{|c|c|c|c|c|c|c|c|c|}
\hline Resistência & - & - & 81 & - & 98 & 92 & 60 & 41 \\
\hline Fuga de Presos & - & - & 100 & - & 119 & 83 & 56 & 56 \\
\hline Desobediência & - & - & - & - & - & - & - & 2 \\
\hline Falsidade & - & - & - & - & - & - & - & 7 \\
\hline Peita & - & - & - & - & - & - & - & 2 \\
\hline Perjúrio & - & - & - & - & - & - & - & 11 \\
\hline $\begin{array}{l}\text { Destruição de prédios } \\
\text { públicos }\end{array}$ & - & - & - & - & - & - & - & 3 \\
\hline \multicolumn{9}{|l|}{ Causas } \\
\hline Vadios & - & - & - & - & 106 & - & - & - \\
\hline Mendigos & - & - & - & - & 14 & - & - & - \\
\hline Embriaguez habitual & - & - & - & & 86 & - & - & - \\
\hline Prostitutas & - & - & - & - & 60 & - & - & - \\
\hline Turbulentos & - & - & - & - & 146 & - & - & - \\
\hline \multicolumn{9}{|l|}{$\begin{array}{l}\text { Crimes contra a } \\
\text { Personalidade }\end{array}$} \\
\hline Homicídio & - & 471 & 474 & - & 619 & 586 & 500 & 544 \\
\hline Tentativas de Homicídio & - & 167 & 210 & - & 203 & 228 & 222 & 215 \\
\hline Ofensas Físicas & - & 1.126 & 1.126 & - & 1.611 & 1.394 & 1.253 & 1.290 \\
\hline Calúnias e Injúrias & - & - & - & - & 359 & 270 & 240 & 218 \\
\hline Ameaças & - & - & - & - & 111 & 85 & 77 & 42 \\
\hline Estupros & - & - & - & - & 65 & 67 & 78 & 59 \\
\hline Raptos & - & - & - & - & - & - & - & 16 \\
\hline Diversos & - & - & - & - & 64 & 54 & 54 & 20 \\
\hline \multicolumn{9}{|l|}{$\begin{array}{c}\text { Crimes contra a } \\
\text { Propriedade }\end{array}$} \\
\hline Furtos & - & 369 & 252 & - & 586 & 343 & 423 & 142 \\
\hline Roubos & - & 109 & 147 & - & 167 & 173 & 131 & 139 \\
\hline Danos & - & - & - & - & 147 & 152 & 114 & 90 \\
\hline Estelionatos & - & 93 & 73 & - & 129 & 122 & 71 & 34 \\
\hline \multicolumn{9}{|l|}{ Termos de bem-viver } \\
\hline Assignados $^{8}$ & - & - & 214 & - & 415 & 275 & 314 & 224 \\
\hline Nacionais & - & - & 137 & - & - & 188 & 193 & 170 \\
\hline Estrangeiros & - & - & 77 & - & - & 87 & 121 & 54 \\
\hline Maiores & - & - & - & - & - & 261 & 286 & 209 \\
\hline Menores & - & - & - & - & - & 14 & 28 & 15 \\
\hline Homens & - & - & - & - & - & 210 & 268 & 149 \\
\hline Mulheres & - & - & - & - & - & 65 & 46 & 75 \\
\hline \multicolumn{9}{|l|}{$\begin{array}{c}\text { Natureza de crimes } \\
\text { policiais }\end{array}$} \\
\hline Ofensa à religião e à moral & - & - & - & - & - & - & - & 10 \\
\hline Armas proibidas & - & - & - & - & 148 & - & - & 28 \\
\hline Vadiação & - & - & - & - & 201 & - & - & 10 \\
\hline
\end{tabular}

Fonte: CASTRO, 1894, p. 15-24.

Acreditamos que por meio do quadro da organização dos dados que nos debruçamos em apresentar a partir dos números sistematizados por Viveiros de Castro, contribuiremos para melhor visibilidade dos números do crime no Brasil de 1865 a 1872.

Por certo, que não temos a pretensão de discutirmos proficuamente os crimes ocorridos no Brasil no intervalo dos anos sobreditos, esta análise se desdobraria em diversas outras pesquisas. O material que estamos disponibilizando poderá contribuir em suas elaborações. Entretanto, nos salta aos olhos e não podemos deixar de destacar a comparação

desuso. É o mesmo que assinar.

É uma expressão da Língua Portuguesa que atualmente está em

ISSN: $2175-0742$ | v. 22 | n. 39 | p. 161-186 | Jan. / Jun. 2020 
entre o quantitativo de crimes cometidos em sua totalidade aos números dos processos que foram abertos para apurar as transgressões ocorridas. Houve descontinuidade das averiguações dos crimes até o judiciário.

Para essa análise destacamos alguns indícios nos números expostos na tabela.

Em 1866 foram registrados 3.400 crimes, mas só foram efetuados 2.528 processos criminais. O que nos indicou que 827 processos deixaram de ser abertos e transgressões deixaram de ser averiguadas, julgadas e punidas nos tribunais de justiça.

A mesma situação também pode ser constatada nos dados apurados dos crimes cometidos em 1865 quando deixaram de ser abertos 44 processos. Em 1867 não passaram para âmbito jurídico 709 crimes. Em 1870 os números foram mais significativos, pois identificamos que cerca da quinta parte dos detidos não foram processados. Em 1871 os números de transgressões sem deliberações processuais chegaram a 1.003, quantitativo expressivo. Em 1872 foram 785 transgressões penais que não chegaram às instâncias jurídicas.

Esses números díspares entre a detenção e o desdobramento em processo criminal podem ser explicados pelo afastamento do crime em si. Isso é, havia um fosso entre a infração à lei da legislação criminal, da prática da repressão pelo poder público do crime de fato. A situação decorria do aparato policial que na tentativa de ter o controle social acabaria por realizar prisões sem a existência de amparo legal. Logo o preso seria solto por não ter justificativa para a reclusão.

Essa lacuna entre as estatísticas de presos e a real existência do crime nos foi evidenciada por Boris Fausto (1984, p. 18-25). O historiador nos indicou que o hiato entre a atividade policial e a judiciária não se daria somente por razões meramente técnicas. Mas se daria, também, pela discriminação social e pelas orientações políticas de repressão. Em suas pesquisas sobre o crime exemplificou que havia prisão de homossexuais sob diferentes pretextos porque a prática repressiva selecionaria, individualizaria e criminalizaria condutas hesitantes pela perspectiva penal.

Os números não fechariam porque ocorriam prisões arbitrárias que não se sustentariam ante as leis penais. Não existia crime de fato ou provas do crime. Por isso, não havia possibilidade de prosseguir com desdobramento de processo criminal. Recaía na ilegalidade por conta da conduta repressora das autoridades policiais.

\section{Os dados do crime no Rio de Janeiro}


Quanto a organização dos dados estatísticos dos crimes ocorridos no Distrito Federal Rio de Janeiro - entre os anos de 1870 e 1888, Viveiros de Castro nos evidenciou elementos que foram além da observância da dinâmica dos crimes em números. Ele expôs as suas considerações sobre os transgressores penais, o que nos proporcionou o acesso a sua percepção da sociedade carioca naquele recorte temporal.

Para efeito de análise e confrontamento também apresentaremos os números dos censos da população do Rio de Janeiro nos anos de 1872 e 1890, períodos aproximados dos dados estatísticos organizados por Francisco José Viveiros de Castro.

A cidade do Rio de Janeiro, Distrito Federal, no censo de 1872 registrou 274.972 habitantes e no censo de 1890, a população saltou para 522.651 habitantes (IBGE, 1996).

Esse salto numérico considerável ocorrido no Distrito Federal foi motivado por diversos fatores: a aceleração do processo migratório de ex-escravizados da área rural para a urbana, a intensificação da imigração e a melhoria nas condições de saneamento que possibilitou a diminuição de óbitos (CHALHOUB, 2001, p. 43; LOBO, 1978, p. 469).

Isso posto, mostraremos abaixo os dados da criminalidade no Rio de Janeiro de 1872 a 1888. Com o objetivo de tornar mais compreensível a nossa organização, separamos os anos por décadas. Iniciaremos com o panorama do crime na Capital Federal de 1870 a 1879 , com a ausência de dados dos anos de 1875 e 1876 que, segundo o juiz Francisco José Viveiros de Castro, as referências não foram encontradas nos relatórios do Ministério da Justiça e da Chefatura (CASTRO, 1894, p. 37).

\section{Quadro II}

Dados da organização dos crimes e criminosos no Rio de Janeiro de 1870-1879

\begin{tabular}{|c|c|c|c|c|c|c|c|c|}
\hline Anos & 1870 & 1871 & 1872 & 1873 & 1874 & 1877 & 1878 & 1879 \\
\hline Crimes & & & & & & & & \\
\hline Homicídio & 17 & 16 & - & 23 & 20 & - & - & 25 \\
\hline $\begin{array}{c}\text { Tentativa de } \\
\text { Homicídio }\end{array}$ & 8 & 2 & - & - & 6 & - & - & 7 \\
\hline Ferimentos graves & 45 & 23 & - & - & - & - & - & 15 \\
\hline Casa de Detenção & & & & & & & & \\
\hline Recolhidos & 2.901 & 2.793 & 2.024 & 2.011 & 3.292 & 5.230 & 5.834 & 6.832 \\
\hline Livres & 1.620 & 1.489 & 903 & 866 & 1.076 & 3.212 & 4.008 & 5.028 \\
\hline Escravos & 1.281 & 1.304 & 1.121 & 1.145 & 2.216 & 2.018 & 1.826 & 1.804 \\
\hline Homens & 2.540 & 2.441 & 1.728 & 1.107 & 2.636 & - & - & 5.672 \\
\hline Mulheres & 361 & 352 & 296 & 304 & 656 & - & - & 1.160 \\
\hline Nacionais & - & - & - & - & - & - & - & 4.467 \\
\hline
\end{tabular}


Fronteiras: Revista de História

A estatística do crime no oitocentos por Francisco José Viveiros de Castro: dados do Brasil e do Rio de Janeiro Adriana Gomes

\begin{tabular}{|c|c|c|c|c|c|c|c|c|}
\hline Estrangeiros & - & - & - & - & - & - & - & 2.365 \\
\hline \multicolumn{9}{|l|}{ Prisão na polícia ${ }^{9}$} \\
\hline Recolhidos & 7.015 & 7.380 & 7.652 & 7.341 & 8.778 & 10.376 & 10.072 & 8.815 \\
\hline Livres & 4.730 & 4.512 & 4.733 & 4.315 & 6.337 & 7.917 & 7.925 & 6.999 \\
\hline Escravos & 2.375 & 2.768 & 2.919 & 3.026 & 2.441 & 2.459 & 2.147 & 1.816 \\
\hline Homens & 6.173 & 6.289 & 6.668 & 6.671 & 7.665 & 8.530 & - & 7.282 \\
\hline Mulheres & 932 & 991 & 984 & 670 & 1.113 & 1.846 & - & 1.533 \\
\hline \multicolumn{9}{|l|}{ Casa de Correção } \\
\hline Existiam & 119 & 123 & 149 & 137 & 223 & 145 & 273 & 268 \\
\hline Entraram & 30 & 65 & 27 & - & 107 & 58 & 300 & 279 \\
\hline Cumpriram penas & 23 & 31 & 35 & - & 82 & 40 & 302 & 245 \\
\hline Foram perdoados & - & 5 & 3 & - & 5 & 6 & 2 & 2 \\
\hline Faleceram & 3 & 2 & 5 & - & 6 & 7 & 13 & 9 \\
\hline Foram transferidos & - & 1 & 2 & - & 1 & 5 & - & 3 \\
\hline Ficaram existindo & 123 & - & - & - & - & - & - & 288 \\
\hline Evadiu-se & - & - & - & - & 1 & & - & - \\
\hline Total & 149 & - & - & - & - & & - & - \\
\hline \multicolumn{9}{|l|}{ Nacionalidade } \\
\hline Brasileiros & 63 & 81 & 78 & 58 & 154 & - & - & 150 \\
\hline Portugueses & 62 & 72 & 66 & - & 103 & - & - & - \\
\hline Franceses & 4 & 7 & 6 & - & 4 & - & - & - \\
\hline Espanhóis & 4 & 5 & 2 & - & 3 & - & - & - \\
\hline Italianos & 4 & 4 & 4 & - & 10 & - & - & - \\
\hline Ingleses & 2 & 3 & 3 & - & 1 & - & - & - \\
\hline Prussiano & 1 & 1 & 1 & - & 1 & - & - & - \\
\hline Americano & 1 & 3 & 2 & - & 2 & - & - & - \\
\hline Oriental & 1 & - & - & - & - & - & - & - \\
\hline Chineses & 1 & 2 & 2 & - & 1 & - & - & - \\
\hline Africanos & 6 & 6 & 7 & - & 11 & - & - & - \\
\hline Montevideanos & - & 2 & 2 & - & 2 & - & - & - \\
\hline Suíços & - & 2 & 2 & - & 2 & - & - & - \\
\hline Grego & - & - & - & - & 1 & - & - & - \\
\hline Argentinos & - & - & - & - & 2 & - & - & - \\
\hline Estrangeiros & - & - & - & 79 & - & - & - & 129 \\
\hline \multicolumn{9}{|l|}{ Escolaridade } \\
\hline Alfabetizados & 83 & 105 & 94 & - & 158 & - & 131 & 127 \\
\hline Analfabetos & 66 & 83 & 82 & - & 172 & - & 169 & 152 \\
\hline \multicolumn{9}{|l|}{ Faixa etária } \\
\hline Maiores de 30 anos & 73 & - & - & - & - & - & - & - \\
\hline Menores de 30 anos & 76 & - & - & - & - & - & - & - \\
\hline Menores de 20 anos & - & 25 & 30 & - & - & - & 46 & - \\
\hline Maiores de 21 anos & - & - & - & - & - & - & - & 44 \\
\hline De 21 a 30 anos & - & 63 & - & - & - & - & - & - \\
\hline De 21 a 40 anos & - & - & 125 & - & - & - & 205 & 194 \\
\hline De 31 a 40 anos & - & 64 & - & - & - & - & - & - \\
\hline Maiores de 40 anos & - & - & 21 & - & - & - & 39 & 41 \\
\hline De 41 a 50 anos & - & 29 & - & - & - & - & - & - \\
\hline De 51 a 60 anos & - & 6 & - & - & - & - & - & - \\
\hline
\end{tabular}

No livro Estatísticas Criminais, o termo utilizado era xadrez de polícia.

ISSN: $2175-0742$ | v. 22 | n. 39 | p. 161-186 | Jan. / Jun. 2020 
Fronteiras: Revista de História

A estatística do crime no oitocentos por Francisco José Viveiros de Castro: dados do Brasil e do Rio de Janeiro Adriana Gomes

\begin{tabular}{|c|c|c|c|c|c|c|c|c|}
\hline Maior de 60 & - & 1 & - & - & - & - & - & - \\
\hline \multicolumn{9}{|l|}{ Estado Civil } \\
\hline Solteiros & - & - & 138 & - & 268 & - & 267 & 252 \\
\hline Casados & - & - & 31 & - & 52 & - & 30 & 22 \\
\hline Viúvos & - & - & 7 & - & 10 & - & 3 & 5 \\
\hline \multicolumn{9}{|l|}{ Natureza dos Crimes } \\
\hline $\begin{array}{l}\text { Crime contra a } \\
\text { personalidade }\end{array}$ & 57 & - & - & 72 & - & - & 76 & - \\
\hline $\begin{array}{l}\text { Crime contra a } \\
\text { propriedade }\end{array}$ & 68 & - & - & 65 & - & - & 53 & - \\
\hline Ameaça & - & - & - & - & 1 & - & - & - \\
\hline Estelionato & - & - & - & - & 17 & - & - & - \\
\hline Ofensas Físicas & - & - & - & - & 14 & - & - & - \\
\hline Furtos & - & - & - & - & 23 & - & - & - \\
\hline Homicídios & - & - & - & - & 60 & - & - & - \\
\hline Moeda Falsa & - & - & - & - & 1 & - & - & - \\
\hline Quebra Fraudulenta & - & - & - & - & 1 & - & - & - \\
\hline Raptos & - & - & - & - & 7 & - & - & - \\
\hline Resistência & - & - & - & - & 1 & - & - & - \\
\hline Roubos & - & - & - & - & 41 & - & - & - \\
\hline $\begin{array}{l}\text { Tentativas de } \\
\text { Homicídio }\end{array}$ & - & - & - & - & 3 & - & - & - \\
\hline Tentativa de Roubo & - & - & - & - & 1 & - & - & - \\
\hline $\begin{array}{l}\text { Uso de instrumentos } \\
\text { para roubar }\end{array}$ & - & - & - & - & 3 & - & - & - \\
\hline Quebra do Termo & - & - & - & - & - & - & 171 & - \\
\hline
\end{tabular}

Fonte: CASTRO, 1894, p. 29-41.

Dando continuidade à apresentação dos dados da criminalidade obtidos nas estatísticas, evidenciaremos os números dos anos de 1880 a 1888 , que finalizou a organização realizada por Viveiros de Castro.

Quadro III

Dados da organização dos crimes e criminosos no Rio de Janeiro de 1880-1888

\begin{tabular}{|c|c|c|c|c|c|c|c|c|c|}
\hline Anos & 1880 & 1881 & 1882 & 1883 & 1884 & 1885 & 1886 & 1887 & 1888 \\
\hline Crimes & & & & & & & & & \\
\hline Homicídio & 22 & 16 & 17 & 20 & 12 & 9 & 25 & 21 & 21 \\
\hline $\begin{array}{c}\text { Tentativa de } \\
\text { Homicídio }\end{array}$ & 4 & - & 11 & 9 & 9 & 7 & 3 & 9 & 10 \\
\hline $\begin{array}{c}\text { Ferimentos } \\
\text { graves }\end{array}$ & - & - & 10 & 11 & - & - & 14 & 9 & 21 \\
\hline $\begin{array}{c}\text { Casa de } \\
\text { Detenção }\end{array}$ & & & & & & & & & \\
\hline Recolhidos & 7.518 & 8.380 & 8.077 & 8.469 & 7.862 & 8.377 & 9.435 & 10.476 & 5.841 \\
\hline Livres & 5.857 & 6.749 & - & 6.807 & 6.323 & - & - & 10.072 & - \\
\hline Escravos & 1.661 & 1.631 & - & 1.662 & 1.539 & - & - & 404 & - \\
\hline Homens & 6.595 & 7.186 & - & - & - & - & - & - & - \\
\hline Mulheres & 923 & 1.194 & - & - & - & - & - & - & - \\
\hline Nacionais & 4.911 & 5.234 & - & - & - & - & - & - & - \\
\hline
\end{tabular}


Fronteiras: Revista de História

A estatística do crime no oitocentos por Francisco José Viveiros de Castro: dados do Brasil e do Rio de Janeiro Adriana Gomes

\begin{tabular}{|c|c|c|c|c|c|c|c|c|c|}
\hline Estrangeiros & 2.607 & 3.146 & - & - & - & - & - & - & - \\
\hline \multicolumn{10}{|l|}{$\begin{array}{l}\text { Prisão na } \\
\text { polícia }^{10}\end{array}$} \\
\hline Recolhidos & 7.107 & 5.114 & 5.223 & 6.149 & 6.565 & 5.221 & 9.041 & 7.491 & 4.751 \\
\hline Livres & 5.632 & 4.083 & 3.842 & 5.046 & 5.474 & 4.198 & 8.175 & 6.838 & - \\
\hline Escravos & 1.475 & 1.031 & 1.381 & 1.103 & 1.091 & 1.023 & 866 & 653 & - \\
\hline Homens & 5.893 & 4.152 & 4.122 & - & 5.449 & 4.183 & 7.462 & 6.476 & - \\
\hline Mulheres & 1.214 & 962 & 1.101 & - & 1.116 & 1.038 & 1.579 & 1.015 & - \\
\hline \multicolumn{10}{|l|}{$\begin{array}{l}\text { Casa de } \\
\text { Correção }\end{array}$} \\
\hline Existiam & 293 & 278 & - & 223 & - & 238 & 254 & 261 & 273 \\
\hline Entraram & 271 & 221 & - & 197 & - & 154 & 133 & 156 & 281 \\
\hline $\begin{array}{c}\text { Cumpriram } \\
\text { penas }\end{array}$ & 263 & 241 & - & 196 & - & - & 106 & 119 & 206 \\
\hline $\begin{array}{c}\text { Foram } \\
\text { perdoados }\end{array}$ & 3 & - & - & 1 & - & 3 & 3 & 3 & 6 \\
\hline Faleceram & 15 & 7 & - & 6 & - & 4 & 13 & 18 & 12 \\
\hline $\begin{array}{c}\text { Foram } \\
\text { transferidos }\end{array}$ & 4 & 15 & - & 1 & - & 9 & 3 & 2 & 4 \\
\hline $\begin{array}{l}\text { Ficaram } \\
\text { existindo }\end{array}$ & 277 & 236 & - & 216 & - & - & - & - & - \\
\hline Evadidos & 2 & - & - & - & - & - & - & - & - \\
\hline Total & - & - & - & - & - & - & - & - & - \\
\hline \multicolumn{10}{|l|}{ Nacionalidade } \\
\hline Brasileiros & 155 & 134 & - & 2.533 & - & 219 & - & - & - \\
\hline Estrangeiros & 116 & 83 & - & 2.513 & - & 173 & - & - & - \\
\hline \multicolumn{10}{|l|}{ Escolaridade } \\
\hline Alfabetizados & 105 & 95 & - & - & - & 87 & - & 193 & 290 \\
\hline Analfabetos & 166 & 122 & - & - & - & 305 & - & 224 & 264 \\
\hline \multicolumn{10}{|l|}{$\begin{array}{c}\text { Gênero dos } \\
\text { detentos }\end{array}$} \\
\hline Homens & - & - & - & - & - & 378 & 369 & 403 & - \\
\hline Mulheres & - & - & - & - & - & 14 & 18 & 14 & - \\
\hline \multicolumn{10}{|l|}{ Faixa etária } \\
\hline $\begin{array}{c}\text { Maiores de } 30 \\
\text { anos }\end{array}$ & - & - & - & - & - & - & - & - & - \\
\hline $\begin{array}{c}\text { Menores de } 30 \\
\text { anos }\end{array}$ & - & - & - & - & - & - & - & - & - \\
\hline $\begin{array}{c}\text { Menores de } 14 \text { a } \\
20 \text { anos }\end{array}$ & - & - & - & - & - & 58 & - & - & - \\
\hline $\begin{array}{c}\text { Menores de } 20 \\
\text { anos }\end{array}$ & - & - & - & - & - & - & - & - & - \\
\hline $\begin{array}{c}\text { Menores de } 21 \\
\text { anos }\end{array}$ & 46 & 22 & - & - & - & - & 72 & - & 101 \\
\hline De 21 a 30 anos & - & - & - & - & - & - & - & - & - \\
\hline De 21 a 40 anos & 179 & 157 & - & - & - & 260 & 245 & - & 326 \\
\hline De 31 a 40 anos & - & - & - & - & - & - & - & - & - \\
\hline $\begin{array}{c}\text { Maiores de } 40 \\
\text { anos }\end{array}$ & 46 & 38 & - & - & - & 74 & - & - & - \\
\hline De 41 a 50 anos & - & - & - & - & - & - & - & - & - \\
\hline De 40 a 60 anos & - & - & - & - & - & - & - & - & 116 \\
\hline De 51 a 60 anos & - & - & - & - & - & - & - & - & - \\
\hline Maiores de 60 & - & - & - & - & - & - & - & - & 11 \\
\hline Estado Civil & & & & & & & & & \\
\hline
\end{tabular}

No livro Estatísticas Criminais, o termo utilizado era xadrez de polícia.

ISSN: $2175-0742$ | v. 22 | n. 39 | p. 161-186 | Jan. / Jun. 2020 


\begin{tabular}{|c|c|c|c|c|c|c|c|c|c|}
\hline Solteiros & 241 & 190 & - & - & - & 319 & 319 & 347 & 481 \\
\hline Casados & 22 & 20 & - & - & - & 59 & 52 & 55 & 54 \\
\hline Viúvos & 8 & 7 & - & - & - & 14 & 16 & 15 & 19 \\
\hline $\begin{array}{l}\text { Natureza dos } \\
\text { Crimes }\end{array}$ & & & & & & & & & \\
\hline $\begin{array}{l}\text { Crime contra a } \\
\text { personalidade }\end{array}$ & - & - & - & - & - & 202 & 151 & - & 240 \\
\hline $\begin{array}{c}\text { Crime contra a } \\
\text { propriedade }\end{array}$ & - & - & - & - & - & 142 & 137 & - & 145 \\
\hline
\end{tabular}

Fonte: CASTRO, 1894, p. 41-51.

De maneira geral, entre 1870 e 1888 foram registrados 264 crimes, 85 tentativas de homicídio e 148 ferimentos graves. Nas Casas de Detenções ficaram retidos 105.352 cidadãos discriminados em 54.010 de pessoas libertas e 19.682 de pessoas escravizadas sendo 29.788 homens e 5.246 mulheres (CASTRO, 1894, p. 52).

Foram levados a prisão ${ }^{11} 125.116$ pessoas, sendo 90.804 livres, 28.574 escravizados. Destas 87.015 eram homens e 15.603 eram mulheres. Para as Casas de Correção foram levadas 798 pessoas por crimes contra a personalidade e 610 por crimes contra a propriedade. (CASTRO, 1894, p. 52).

Em se tratando de acesso à educação, foram listados 1.663 criminosos alfabetizados e 1.997 analfabetos. Quanto ao estado civil, foram pautados serem 2.822 solteiros, 397 casados e 104 viúvos, que distribuídos por faixa etária ficaram enumerados em 516 menores de 21 anos, 2.068 entre 21 e 40 anos de idade e 587 transgressores penais maiores de 40 anos (CASTRO, 1894, p. 52-53).

A partir dos números revelados por Viveiros de Castro obtidos nos relatórios do Ministério da Justiça e da Chefatura que não haviam sido compilados para o estudo do crime, o juiz nos evidenciou suas considerações acerca da estatística criminal, sem privar de nos assenhorear de suas interpretações quanto aos crimes decorridos sob o arcabouço teórico de suas percepções jurídicas.

\section{Ponderações da Estatística Criminal por Francisco José Viveiros de Castro}

A partir da organização dos números do crime, Viveiros de Castro se debruçou em fazer uma breve leitura da estatística com propósito de submeter a sua compreensão ante a dinâmica da criminalidade com destaque para o Rio de Janeiro. De antemão o juiz considerou que suas ponderações não teriam a pretensão de serem definitivas. Pelo contrário, sua proposta seria sinalizar caminhos por meio de seu entendimento sobre as transgressões penais 
com o propósito de prover ações a partir das sinalizações expostas nos estudos estatísticos (CASTRO, 1894, p. 5).

A inquietude do juiz oitocentista na identificação da necessidade de se analisar a estruturação do crime, permanece até os dias atuais. Entretanto, a organização e a proposta na interpretação dos dados passaram por uma série de mudanças, mas a importância das referências estatísticas e a necessidade operacional ante os elementos permanecem.

Segundo o especialista contemporâneo em segurança pública Renato Sérgio de Lima (2008, p. 65), as estatísticas criminais viabilizariam o acesso a mensuração dos crimes e ainda forneceriam subsídios para a tomada de decisões. $\mathrm{O}$ fato permitiria que o planejamento de políticas de ordem pública, poderiam ser eficazes por disponibilizarem de informações indeléveis sobre os transgressores e as transgressões a fim de que os combates aos crimes e aos criminosos pudessem ser realizados com inteligência pelas definições de procedimentos, regras, categorias, entre outras referências que sinalizariam os rumos e os sentidos das políticas para melhor ordenamento da sociedade.

Nessa linha, Viveiros de Castro também pontuou que os dados estatísticos teriam contribuição aos serviços dos legisladores, assim como dos estudiosos do crime que tivessem o propósito de tentar combater a criminalidade. As análises pormenorizadas dos dados poderiam ser fontes diretas de entendimento da dinâmica do crime. Todavia, o magistrado ressaltou que somente olhar os números sem qualquer contextualização poderiam induzir os agentes sobreditos em uma série de equívocos (CASTRO, 1894, p. 5).

Os dados coletados precisariam ser analisados com cientificamente para não se perfazerem em "ilusões funestas". Segundo Viveiros de Castro, as imprecisões estariam, justamente, nas precipitações de se concluir por meio de análises prematuras (CASTRO, 1894, p. 5).

A partir dessa linha de pensamento, o juiz criminalista elucubrou que algumas premissas deveriam ser respeitadas para que houvesse empregabilidade responsável dos dados estatísticos do ponto de vista do Direito e da ética social. Para tanto, o juiz compreendeu que seria necessário se levar em consideração tanto o movimento da criminalidade evidenciada nos dados quanto a atuação e a dinâmica do legislativo ante as transgressões (CASTRO, 1894, p. 5-6).

Concomitantemente a isso, deveria se verificar as ações dos agentes de segurança pública, pois eles que atuariam no momento inicial com os transgressores. A análise de cifras 
absolutas sem levar em consideração as circunstâncias acima seria um sério equívoco e de nada contribuiria para o combate ao crime (CASTRO, 1894, p. 5).

Decerto que a organização dos dados efetuados por Viveiros de Castro teve relevante mérito tanto pelas dificuldades logísticas em se organizar os dados descompostos de diversos anos, quanto pelos resultados obtidos para a tomada de decisões que poderiam ter sido providenciadas em combate ao crime. Mas a interpretação dos números estaria distante de se compreender a sociedade e os problemas de seu tempo pelas limitações provenientes da “criminalidade real" (FAUSTO, 1984, p. 19-20).

Como foi o Chefe da Polícia do Distrito Federal Manuel Prisciliano de Oliveira Valladão que solicitou a Francisco José Viveiros de Castro a estruturação da estatística criminal, presumimos que a intenção da autoridade policial era utilizar os dados coletados para a implementação de ações que pudessem, de alguma forma, reduzir a criminalidade no país com destaque para o Rio de Janeiro.

$\mathrm{O}$ que nos interpelamos seria entender que crimes inquietariam tanto o chefe da polícia ao ponto de solicitar o trabalho realizado por Viveiros de Castro que se debruçou em verificar a tipificação e a quantificação dos crimes e dos criminosos, para que o cenário da criminalidade ficasse esquadrinhado para Manuel Prisciliano.

O que podemos afirmar a respeito é que havia intensa preocupação em classificar e controlar a população para que os segmentos sociais mais favorecidos adequassem a ordem desejada nas áreas urbanas. Para controlar os indesejáveis e assegurar os privilégios seria necessário que o Rio de Janeiro deixasse para trás a desprezível associação de ser uma cidade sem segurança ao ponto de exportar criminosos para outros estados, pois essa era a fama que a Capital Federal tinha nos anos finais do oitocentos em São Paulo (FAUSTO, 1984, p. 15).

E a polícia seria importante peça para essa engrenagem funcionar em prol do controle social. A implementação de um projeto de repressão dos mais favorecidos preservaria a ordem estabelecida para a sociedade carioca em sua inserção compulsória na belle époque da cidade do Rio de Janeiro na virada do século XIX para o XX (SEVCENKO, 1983, p. 75; BRETAS, 2018, p. 32-34).

Com esse panorama, Viveiros de Castro considerou ser irrefutável a necessidade de ocorrerem intervenções sérias e eficazes pelos agentes sociais aos envolvidos com a legislação penal. Em suas reflexões destacou a importância da apropriação dos números do crime para se estruturar mecanismos de gestão de segurança associadas a ações investigativas que pudessem fornecer informações desdobradas em procedimentos e práticas preventivas 
que controlassem a criminalidade. Para isso, seria necessário estabelecer mudanças de referências e diretrizes organizacionais que pudessem intervir no comportamento, na dinâmica e na operacionalidade das instituições policiais (AZEVEDO; RICCIO; RUEDIGER, 2011, p. 10-11).

Vale ressaltar que Francisco José Viveiros de Castro foi um dos muitos juristas brasileiros que abraçou os pensamentos criminológicos do século XIX, em especial de Cesare Lombroso (1835-1909), Enrico Ferri (1856-1929) e Garolafo (1851-1934). Entretanto, Viveiros de Castro também mostrou apreço pelas pressuposições de Gabriel Tarde (18431904) e Alexandre Lacassagne (1843-1924), apesar de suas percepções acerca do crime irem de encontro, sobretudo, às ideias lombrosianas (ALVAREZ, 2003, p. 72).

Apesar de se posicionar como seguidor da Antropologia Criminal, Viveiros de Castro em diversas oportunidades usaria a autoridade dos argumentos de Lacassagne, Tarde, entre outros. Principalmente quando os pensamentos desses se adequassem melhor naquilo que ele considerasse o mais coerente na leitura do caso. A situação nos faz endossar as percepções de Schwarcz (2008, p. 19) quando afirmou que o desafio no Brasil no entendimento das teorias europeias não seria tanto absorvê-los por completo, mas criar uma combinação de ideias em um esforço de adaptação de algumas e realizar o descarte outras que pudessem soar de maneira estranha e, assim, criar um pensamento próprio a partir de apropriações e refutações.

Assim posto, com o propósito de fornecer fundamentos que corroborassem na elaboração de ações práticas no combate à criminalidade, Viveiros de Castro realizou uma série de considerações sob aporte hermenêutico das pressuposições criminológicas da Nova Escola Penal. A sua expectativa não era simplesmente evidenciar os números, mas orientar aqueles que tivessem interesse em compreender o processo e a diligência do crime por sua interpretação criminológica.

Em suas análises com o intuito de colaborar com ações de combate ao crime, Viveiros de Castro expôs que os agentes de segurança e da lei deveriam ficar atentos ao clima, pois este influenciara na tipificação do crime. Segundo o juiz, os delitos contra a personalidade seriam mais recorrentes no verão. Já no inverno, os números cairiam vertiginosamente. Em contraposição, os atentados contra a propriedade aumentariam no inverno e diminuiriam no verão (CASTRO, 1894, p. 4).

Apesar da afirmação de que o clima teria alguma interferência na tipificação da composição do crime, Viveiros de Castro não apresentou argumentos que sustentassem a sua interpretação, visto que os dados estatísticos não apresentaram nada nesse sentido. 
Esse entendimento de que o clima interferiria no crime fazia parte do arcabouço teórico-metodológico de Enrico Ferri. Cesare Lombroso também fez considerações a respeito, mas sem colocar o clima como fator que pudesse incrementar a criminalidade (LOMBROSO, 2010, p. 8; FERRI, 2006a, p. 34).

Lombroso considerava o clima e a vida social como fatores exógenos da gênese criminal. Os fatores endógenos que desencadeariam o crime porque o determinismo biológico que o promoveria, na acepção de que o criminoso já nasceria criminoso (PENTEADO FILHO, 2015, p. 50-51; LOMBROSO, 2010, p. 8).

Enquanto Ferri já considerava o clima um elemento importantíssimo na composição da análise da criminalidade. Para ele a temperatura anual associada a diferentes fatores como a "raça", a "produção agrícola", a "aglomeração de povoações", entre outros, deveriam ser aspectos a serem considerados ao se analisar o crime cometido. Ele entendia que o entorno na vida do indivíduo contribuiria para a propensão ao delito e até ao tipo de crime a ser praticado (FERRI, 2006a, p. 34-35).

Quanto ao acesso à educação, Viveiros de Castro não o correlacionava à diminuição da criminalidade. Ele se opunha as argumentações de Alexandre Lacassagne por esse entender que "abrir escolas é fechar cadeias" (CASTRO, 1894, p. 4).

$\mathrm{Na}$ percepção do jurista, a afirmativa seria um "grande equívoco" de Lacassagne, visto que grande parte dos criminosos em diferentes tipos de transgressões penais tiveram em algum momento acesso à escola e teriam grau de instrução. $\mathrm{O}$ acesso aos estudos não impediria a pessoa cometer crimes. Não seria a escolarização que reduziria a criminalidade. A redução das taxas de criminalidade se daria na formação do caráter das pessoas, que se configuraria principalmente no âmbito familiar (CASTRO, 1894, p. 4).

Apesar de refutar as percepções de Lacassagne na questão da escolaridade, Viveiros de Castro se aproximou das argumentações dele nas discussões sobre as questões sociais. $\mathrm{O}$ juiz afirmou que o grande problema que incentivaria o ingresso das pessoas na criminalidade estaria na miséria por essa colocar em xeque a própria negação de acesso às necessidades básicas para a sobrevivência. Assim, ele considerou que o problema da criminalidade não estaria na impossibilidade de se ter acesso à educação escolar, mas no limitado acesso aos recursos essenciais disponíveis para a subsistência junto a um meio de convivência familiar salutar (CASTRO, 1894, p. 4).

A interpretação de Viveiros de Castro foi ao encontro das premissas de Alexandre Lacassagne, porque o professor de Medicina Legal afirmou que tanto os fatores biológicos 
quanto os sociológicos seriam matizes determinantes para o entendimento do comportamento do criminoso. Sob a mesma égide, dariam conta de compreender as possibilidades criminológicas. Nesse sentido, como afirmou Marc Reneville (1995, p. 134), as questões biológicas seriam um fator mesológico indispensável, mas não isolado para Lacassagne.

Não obstante, em aproximação ao Lacassagne o jurista brasileiro compreendia que tanto o lado social quanto o lado biológico seriam faces de uma mesma moeda por entender o criminoso como o "micróbio" da sociedade. E o meio social que o indivíduo viveria seria o "caldo de cultura" para a propagação do crime (SCHECAIRA, 2008, p. 95; RENEVILLE, 1995, p. 130).

Assim, em um ambiente desorganizado a criminalidade encontraria espaço mais favorável para se propagar, em contraposição a um meio social mais organizado. Por isso que uma das sentenças que mais sintetizou as percepções criminológicas de Lacassagne foi a ideia de que 'cada sociedade tem o criminoso que merece'. Viveiros de Castro em sua análise dos dados estatísticos entendeu a criminalidade e as transgressões, também pelo prisma social (SCHECAIRA, 2008, p. 95; RENEVILLE, 1995, p. 130).

Já em relação à penalidade, o jurista criminal pontuou que as perspectivas de Gabriel Tarde (1843-1904) e Rafaelle Garofalo (1851-1934) seriam mais assertivas no combate à criminalidade. Ele compreendeu que as punições deveriam ser de acordo com os delitos. $\mathrm{O}$ que contrapunha com as percepções de Enrico Ferri, que defendia a teoria dos substitutivos (CASTRO, 1894, p. 5).

Gabriel Tarde, em linhas gerais, analisou o comportamento do criminoso a partir da pressuposição que a socialização do indivíduo teria decorrido de forma incorreta e isso possibilitaria a acessibilidade às condutas delituosas. De acordo com as relações interpessoais que teria mantido e as influências sofridas por essas relações, que o criminoso se construiria. Assim, o comportamento delinquente se daria por meio de aprendizagem gradativa. A interlocução preponderante por se constituir um elemento na composição do criminoso em sua prática delitiva. Essa prática seria nada mais do que a evidenciação dos valores dominantes do convívio com aqueles que ensinariam as experiências delituosas. As suas asserções partem do pressuposto que o homem não elaboraria o crime sozinho. Ele precisaria ser habilitado a praticar o comportamento de transgressão (SHECAIRA, 2008, p. 194; TARDE, 1886, p. 34-55).

Já Garofalo, que pode ser considerado o construtor do corpo doutrinário do arcabouço penal da Escola Positiva sob o olhar da justiça se debruçou em analisar o caráter jurídico por 
intermédio de suas instituições com o propósito de conferir significância consistente à concepção de crime. Ele se opôs à criminalidade artificial sob as condições de lugar e tempo, para uma criminalidade com sentido natural em que a benevolência e a probidade eram os sentimentos da natureza humana violados na delinquência (TAVARES, 1970, p. 12; BRUNO, 1984, p. 117; GAROFALO, 1916, p. 264).

Com proposta de outorgar relevância à repressão dos crimes, o tratamento penal proposto por Garofalo seria dar ênfase a repressão de crimes e atribuir aos delituosos o tratamento penal necessário para que a punibilidade fosse proficiente, com a intenção de sustentar um processo inibitório ao crime com as devidas apropriações de sua natureza e não somente procurar os males ocasionados pelo delinquente (BRUNO, 1984, p. 118).

Garofalo redirecionou o foco do criminoso para o próprio crime em si ao criar a noção de "crime natural". As "ações imorais e nocivas que uma sociedade civilizada não deve tolerar", que se fundamentaria o seu corpo teórico. Em contraposição ao conceito de criminoso, o conceito do crime que seria naturalista, pois as ofensas aos sentimentos de piedade $^{12}$, de probidade ${ }^{13}$ e boa-fé pela confiança ${ }^{14}$, que deveriam ser consideradas ações nocivas à sociedade por violarem sentimentos altruístas fundamentais para o convívio da coletividade (GAROFALO, 1916, p. 265; TAVARES, 1970, p. 13; BRUNO, 1984, p. 118).

O conceito jurídico de delito para Garofalo seria a partir dos sentimentos não altruístas. Aquilo que não fosse altruísta apareceria equacionado como sendo "uma violação [...] ofensa feita ao senso moral médio da humanidade civilizada". Os sentimentos altruístas constituiriam o "substrato da moralidade de um povo civilizado" (GAROFALO, 1916, p. 81; p. 86).

A refutação de Viveiros de Castro às percepções de Enrico Ferri deu-se porque o sociólogo em sua teoria de responsabilidade social entendeu que o homem só seria responsável por cometer crimes por ele viver em sociedade. O indivíduo não seria livre tanto quanto o Estado, pois esse teria que recorrentemente impedir penalmente os delitos para a defesa da sociedade e do próprio Direito (FERRI, 2006b, p. 340).

Isso ocorreria porque o Estado não teria condições de "prevenir os delitos, [por] não sabe[r] reprimi-los", por isso só conseguiria refrear os crimes em quantitativo insuficiente.

\footnotetext{
12 Ofensas ao sentimento de piedade: as agressões contra a vida, os crimes que se desdobrassem em mal físico e moral, o defloramento, o rapto, o sequestro, a calúnia, entre outros.

Ofensas ao sentimento de probidade: o roubo, a extorsão dano, os incêndios e as agressões contra a propriedade.

Ofensas ao sentimento de boa-fé e confiabilidade: o estelionato, a apropriação indébita, o plágio, a violação de segredo e a falência fraudulenta.
} 
Assim, acabaria por desempenhar um papel de "reparar as suas expensas os danos acusados", por sua inabilidade na prevenção do "delito e proteger também melhor aos cidadãos". O expediente do Estado seria somente garantir o "mais essencial da seguridade pública", por mero cumprimento de sua função social, porque os cidadãos contribuiriam com impostos. Mas seria uma responsabilidade questionável (FERRI, 2006b, p. 340).

Assim posto, para Enrico Ferri o crime referia-se a um fenômeno social no qual a composição que o imiscuiria seria originária das condições individuais do criminoso que em diversas ocasiões estariam aliadas ao meio físico e social do delituoso, a se considerar onde ele havia nascido, onde vivia e quais lugares ele atuaria. A individualização do criminoso era profusamente evidenciada nas concepções do sociólogo.

A partir das percepções criminológicas evidenciadas em maior ou menor expressividade, Viveiros de Castro ponderou que um de seus maiores propósitos em analisar e compreender os números dos crimes para controlar a criminalidade, foi estabelecer cinco circunstâncias que deveriam ser irrefutavelmente consideradas para a compreensão do crime e do criminoso (CASTRO, 1894, p. 5).

Em primeira análise, o juiz revelou que se tornaria necessário determinar a dinâmica e a atividade do crime para se viabilizar significativamente o controle das transgressões. Por isso, havia a necessidade de processar-se a confluência de intervenções do legislativo em reciprocidade com os agentes da segurança pública (CASTRO, 1894, p. 5-6).

Além disso evidenciou, em sua segunda apreciação, que a ética social deveria ser interpretada a fim de se pontuar os sintomas da criminalidade. Para se identificar as causas e os motivos que promoveram a falta individual do criminoso, seria necessário se analisar com minudência a própria "falta coletiva da sociedade" por considerar que o meio social teria significativa parcela de contribuição para a fomentação da criminalidade (CASTRO, 1894, p. $5-6)$.

Em sua terceira análise sobre o crime e o criminoso, Viveiros de Castro evidenciou que seria indispensável se averiguar os estímulos e circunstâncias que dariam impulso para a tendência do crescente aumento de crimes cometidos por pessoas na juventude (CASTRO, 1894, p. 5-6).

Da mesma maneira, a intelecção do envolvimento de mulheres no mundo do crime. Ademais, ainda ressaltou relevância em se reflexionar sobre o quantitativo expressivo de criminosos reincidentes, o que seria uma evidência da ineficiência do Estado ante a 
recuperação do indivíduo, visto que as punições deferidas não seriam capazes de trazê-lo definitivamente para o convívio social (CASTRO, 1894, p. 6).

Nessa ordem, destacou a ocorrência de crimes cometidos por pessoas de segmentos sociais favorecidos, com "cultura superior" por ir de encontro de encontro a percepção de que a redução da criminalidade estaria associada a formação de caráter promovida pelo meio social que a pessoa conviveria e pelo acesso aos meios de sobrevivência. A ressalva seria que esse meio não foi capaz de promover a formação de caráter com sentimentos altruístas. $\mathrm{O}$ que o levou a considerar que em matéria de se entender o crime e o criminoso não haveria determinismos, mas probabilidades (CASTRO, 1894, p. 6).

Em sua quinta reflexão acerca da criminalidade, o juiz salientou que os problemas sociais tanto quanto os naturais promoveriam a ocorrência de crime. Para ilustrar as suas pressuposições, Viveiros de Castro elucubrou que as causas estariam nos diferentes climas, nas mudanças das estações do ano, no custo elevado dos produtos alimentícios e nas epidemias, que poderiam ser forças motrizes relevantes para o incremento da criminalidade (CASTRO, 1894, p. 6).

Os problemas sociais considerados pelo juiz foram provenientes do aumento da densidade demográfica no Rio de Janeiro associado as dificuldades econômicas, a miséria e a falta de trabalho para os desprovidos do básico. Enquanto poucos usufruiriam muito além do que realmente precisariam. Ele compreendeu que a concentração de renda seria o grande problema a ser resolvido (CASTRO, 1894, p. 6).

Grande parte dos problemas sociais sinalizados por Viveiros de Castro que intensificaram a concentração de renda foram provenientes de mudanças ocorridas no Rio de Janeiro nos anos finais do século XIX. Essas derivaram de transformações econômicas estabelecidas no país. Essas mudanças associadas à transição das relações sociais, sobretudo da escravista para a mão de obra assalariada junto a um processo de intensa imigração, promoveu uma quantidade significativa de pessoas desocupadas permanentemente ou transitoriamente. Isso gerou considerável inconveniente social, que provocou repressão das autoridades policiais na tentativa de controle social (CHALHOUB, 2001, p. 45-46; FAUSTO, 1984, p. 32, 42-43).

Esse controle social tinha um alvo: os menos favorecidos economicamente. A repressão ocorreria entre esses agentes sociais em todas as esferas de suas vidas e cotidianamente. A tentativa de controle para a disciplina rígida levaria a normatização de relações pessoais ou familiares. Nesse contexto a embriaguez foi entendida como 
estimuladora da disciplina e da desordem quando ocorrida entre a população mais pobre (CHALOUB, 2001, p. 51; FAUSTO, 1984, p. 35).

O historiador Boris Fausto $(1984$, p. 36) pontuou que as três contravenções principais na virada do oitocentos foram: embriaguez, desordem e vadiagem. Sendo a embriaguez a motivadora do maior número de prisões, sobretudo de pessoas desprovidas de renda. A prisão por embriaguez foi um instrumento regulador da sociedade para cercear liberdades.

O álcool além de ser considerado um promovedor de agressividade e levar a autodestruição, também foi considerado um potencializador para a consecução de crimes graves. As prisões por embriaguez seriam recorrentes pela "conduta individual perturbadora dos bons costumes", quando assumida por pessoas dos segmentos sociais menos favorecidos independentes da nacionalidade (FAUSTO, 1984, p. 35-38).

Quanto a religião, Viveiros de Castro considerou que a Igreja Católica deveria ser mais atuante na propagação dos costumes com "ética social" a fim de minimizar problemas provocados, sobretudo pela dependência alcóolica e a "corrupção das relações sociais", que seriam reveladas na prostituição, no adultério com o nascimento de "filhos ilegítimos" com a tendência a ruptura do matrimônio (CASTRO, 1894, p. 6).

Em sua última reflexão sobre a criminalidade, o juiz considerou que a "força repressiva e preventiva das leis e do sistema penitenciário" deveriam ser capazes de lidar com todos os problemas derivados do crime. Para Viveiros de Castro, a força repressiva, judiciária e administrativa necessitaria agir simultaneamente com medidas eficazes para a recuperação dos transgressores da lei (CASTRO, 1894, p. 6-7)

Para esse objetivo ser alcançado os trabalhos nas casas de detenção e de correção precisariam ser mais produtivos. Em vez de se preocuparem em somente punir os criminosos teriam que antes prevenir reincidências por meio de ações austeras e contínuas em prol da "ética social" para a "formação do caráter" dos indivíduos. Isso é, disciplinar e enquadrar os detentos dentro das normas sociais estabelecidas, que foram violadas na ocorrência das transgressões (CASTRO, 1894, p. 6-7).

\section{Considerações Finais}

O trabalho de Francisco José Viveiros de Castro foi de grande relevância para a observância do panorama do crime e da criminalidade pela organização dos dados estatísticos 
das transgressões e transgressores do Brasil e do Rio de Janeiro nos recortes temporais que foram disponibilizados.

Além disso, as considerações do jurista nos oportunizaram ter acesso as suas concepções de como poderia ser direcionado o combate à criminalidade: a supressão das privações materiais e emocionais.

Viveiros de Castro destacou que os maiores problemas a serem enfrentados para a inibição do crime seriam as ausências de valores altruísta na formação dos cidadãos e as carências sociais. Essa se apresentaria em diversas ordens, tais como: falta de oportunidade de acesso aos direitos mínimos para o seu sustento, o desprovimento de alicerces familiares para que a educação fosse contemplada em diversas esferas e promovesse a formação de caráter

Ao evidenciar as percepções sobreditas, Francisco José Viveiros de Castro aproximou-se e apropriou-se de perspectivas dos criminológicos europeus Lacassagne e Garofalo. O primeiro no entendimento do ingresso das pessoas ao mundo do crime pela perspectiva social e do segundo, na assimilação de que o principal meio para se combater o crime seria sublimar as imperfeições da personalidade, antes que elas pudessem promover oportunidades de trânsito que facultassem a ingerência de infrações penais.

Reconhecemos que as análises de Viveiros de Castro dos crimes ocorridos no Brasil nas últimas décadas do século XIX estavam imbuídas de percepções de um homem de seu tempo por suas análises criminológicas historicamente pontuadas. Com o olhar de um juiz na virada do século, ele se identificou com as pressuposições da Nova Escola Penal sem ter a preocupação de manter coerência teórico-metodológica.

Ele adequou as ideias europeias as suas próprias leituras de mundo para que políticas fossem impostas à sociedade, a fim de se estabelecer o que se compreendia como ordem pública para o Brasil com destaque para o Rio de Janeiro.

Sem dúvida, o trabalho final de Francisco José Viveiros de Castro entregue ao chefe da polícia do Distrito Federal Manuel Prisciliano de Oliveira Valladão não foram somente números estatísticos meramente apresentados. Houve uma análise que tinha o compromisso de tentar intervir nos problemas de segurança pública sob a perspectiva de um juiz do oitocentos.

Francisco José Viveiros de Castro foi um magistrado situado no oitocentos. Mas isso não o desempossou em ter olhar sensível para os problemas sociais de seu entorno e sugerir intervenções. Ele buscou encontrar soluções para a construção de um futuro que considerasse 
estabelecer medidas na direção da diminuição das diferenças sociais e da concentração de renda entre os brasileiros. Essas medidas já refreariam o crime. E, a partir de então, que se poderia pensar em intervenções eficazes para o combate ao crime.

\section{Referências}

ALVAREZ, Marcos César. Bacharéis, criminologistas e juristas: saber jurídico e Nova Escola Penal no Brasil. São Paulo: IBCCRIM, 2003.

AZEVEDO, Ana Luísa Vieira de; RICCIO, Vicente; RUEDIGER, Marco Aurélio. A utilização das estatísticas criminais no planejamento da ação policial: cultura e contexto organizacional como elementos centrais à sua compreensão. Revista Ciência da Informação, Brasília, v. 40, n. 1, p. 9-21, jan./abr. 2011. Disponível em: http://revista.ibict.br/ciinf/article/view/1321/1500.

BRASIL. Decreto n. 8.375, de 14 de dezembro de 1882. Dá providências sobre a estatística. In: BRASIL. Coleção de Leis do Império do Brasil. Brasília: Imprensa Nacional, 1882. v. 1, parte II, p. 38. Disponível em: https://www2.camara.leg.br/legin/fed/decret/18241899/decreto-8375-14-janeiro-1882-544908-publicacaooriginal-56589-pe.html. Acesso em: 19 abr. 2019.

BRASIL. Decreto n. 7.001, de 17 de agosto de 1878. Manda executar o regulamento da estatística policial e judiciária. In: BRASIL. Coleção de Leis do Império do Brasil. Brasília: Imprensa Nacional, 1878. v. 1, p. 540. Disponível em: https://www2.camara.leg.br/legin/fed/decret/1824-1899/decreto-7001-17-agosto-1878547904-publicacaooriginal-62801-pe.html. Acesso em: 15 abr. 2019.

BRASIL. Decreto n. 3.572, de 30 de dezembro de 1865. Manda executar o regulamento da estatística policial e judiciária. In: BRASIL. Coleção de Leis do Império do Brasil. Brasília: Imprensa Nacional, 1865. v. 1, parte II, p. 422. Disponível em: https://www2.camara.leg.br/legin/fed/decret/1824-1899/decreto-3572-30-dezembro-1865554970-publicacaooriginal-73983-pe.html. Acesso em: 8 abr. 2019.

BRETAS, Marcos Luiz. Guerra das Ruas: povo e polícia na cidade do Rio de Janeiro (18891907). Rio de Janeiro: Gramma, 2018.

BRUNO, Aníbal. Direito penal. Rio de Janeiro: Forense, 1984. Tomo I.

CASTRO, Francisco José Viveiros. Ensaio sobre a estatística criminal da República. Rio de Janeiro: Typografia Leuzinger, 1894.

CHALHOUB, Sidney. Trabalho, lar e botequim. São Paulo: Editora Unicamp, 2001.

DORIA, Epifânio. Centenário de nascimento do General Manuel Prisciliano de Oliveira Valadão. Aracaju: IHGB de Sergipe, 1949.

FAUSTO, Boris. Crime e cotidiano: a criminalidade em São Paulo (1880-1924). São Paulo: Brasiliense, 1984.

FERRI, Enrico. Sociologia criminal. Sorocaba: Minelli, 2006a.

FERRI, Enrico. Delinquente e responsabilidade penal. São Paulo: Rideel, 2006b.

GAROFALO, Raffaele. Criminologia. Lisboa: Livraria Clássica Editora, 1916. 
GOMES, Adriana. Um "crime indígena" ante as normas e o ordenamento jurídico brasileiro: a criminalização do espiritismo e o saber jurídico na Nova Escola Penal de Francisco José Viveiros de Castro (1880-1900). 2017. Tese (Doutorado em História Política e Cultura) - Instituto de Filosofia e Ciências Humanas, Universidade do Estado do Rio de Janeiro, Rio de Janeiro, 2017.

HOLlOWAY, Thomas H. Polícia no Rio de Janeiro: Repressão e resistência numa cidade do século XIX. Rio de Janeiro: FGV Editora, 1997.

INSTITUTO BRASILEIRO DE GEOGRAFIA E ESTATÍSTICA - IBGE. Sinopse do censo demográfico: 1872-2010. Rio de Janeiro: IBGE, 2010. Disponível em: https://censo2010.ibge.gov.br/sinopse/index.php?dados=6. Acesso em: 16 jun. 2019.

INSTITUTO BRASILEIRO DE GEOGRAFIA E ESTATÍSTICA - IBGE. Anuário estatístico do Brasil: 1872-1920. Rio de Janeiro: IBGE, 1996. v. 56. Disponível em: https://ww2.ibge.gov.br/home/estatistica/populacao/censohistorico/1872_1920.shtm. Acesso em: 16 jun. 2019.

LIMA, Renato Sérgio. A produção da opacidade: estatísticas criminais e segurança pública no Brasil. Revista Novos Estudos, n. 80, p. 65-69, mar. 2008. Disponível em: https://www.scielo.br/pdf/nec/n80/a05n80.pdf.

LOBO, Eulalia Maria Lameyer. História do Rio de Janeiro: do capital comercial ao capital industrial e financeiro. Rio de Janeiro: IBMEC, 1978.

LOMBROSO, Cesare. O homem delinquente. São Paulo: Ícone, 2010.

MANUEL Pinto de Sousa Dantas. Biografia e genealogia. [S.l.: s.n.], 2018. Disponível em: https://www.geni.com/people/Senador-Dantas/6000000019924401629. Acesso em: 25 maio 2019.

MOMESSO, Beatriz Piva. O conceito de cidadania nos escritos de Nabuco de Araújo (18431876): notas de pesquisa. In: SIMPÓSIO NACIONAL DE HISTÓRIA ANPUH, 26., 2011, São Paulo. Anais [...]. São Paulo: ANPUH, 2011. p. 1-11.

PENTEADO FILHO. Manual esquemático de criminologia. São Paulo: Saraiva, 2015.

PEREIRA, Lafayette Rodrigues. Direitos de família. Brasília: Senado Federal; Superior Tribunal de Justiça, 2004. Ed. fac-sim.

RENNEVILLE, Marc. Alexandre Lacassagne: un médecin anthropologue face à la criminalité (1843-1924). Gradhiva: revue d'histoire et d'archives de l'anthropologie, Musée du quai Branly, Paris, p. 247-268, 1995.

SCHECAIRA, Sérgio Salomão. Criminologia. São Paulo: Revista dos Tribunais, 2008.

SCHWARCZ, Lilia M. O espetáculo das raças: cientistas, instituições e questão racial no Brasil (1870-1930). São Paulo: Companhia das Letras, 2008.

SEVCENKO, Nicolau. A literatura como missão: tensões sociais e criação cultural na Primeira República. São Paulo: Brasiliense, 1983.

TARDE, Gabriel. La criminalité comparée. Paris: Félix Alcan, 1886.

TAVARES, Oswaldo Hamilton. A Escola Positiva e sua influência na legislação penal brasileira. Revista Justitia. São Paulo, n. 77, p. 7-21, 1970. Disponível em: http://www.revistajustitia.com.br/revistas/994a24.pdf. 